\title{
Validation of Biodegradable Synthetic Small Diameter Arterial Vascular Grafts Using a Large Animal Model
}

\author{
Anudari Ulziibayar ${ }^{1}$, Yuichi Matsuzaki ${ }^{1}$ and Toshiharu Shinoka ${ }^{1,2,3 *}$ \\ ${ }^{1}$ Center for Regenerative Medicine, The Abigail Wexner Research Institute at Nationwide Children's Hospital, Columbus, $\mathrm{OH}$, \\ USA
}

${ }^{2}$ Department of Surgery, Nationwide Children's Hospital, Columbus, OH, USA

${ }^{3}$ Department of Cardiothoracic Surgery, the Heart Center, Nationwide Children's Hospital, Columbus, OH, USA

*Corresponding author: Toshiharu Shinoka, Center for Regenerative Medicine, The Abigail Wexner Research Institute at Nationwide Children's Hospital, Department of Surgery, Department of Cardiothoracic Surgery, the Heart Center The Ohio State University Wexner Medical Center, Columbus, OH, USA

\section{ARTICLE INFO}

Received: 蔧 June 03, 2020

Published: 幽 June 10, 2020

Citation: Anudari U, Yuichi M, Toshiharu S. Validation of Biodegradable Synthetic Small Diameter Arterial Vascular Grafts Using a Large Animal Model. Biomed J Sci \& Tech Res 28(2)-2020. BJSTR. MS.ID.004617.

Keywords: Tissue Engineered Small Diameter Artery; Tissue Engineered Vascular Graft; Biodegradable; Large Animal Model

\section{ABSTRACT}

Cardiovascular disease remains to be the number one killer worldwide and surgical intervention is often necessary for the patient survival. The autologous vascular and traditional prosthetic grafting remains to be the standard approach; however, this procedure has been plagued by several fatal pitfalls, including due to patient comorbidities and repeated bypass surgeries. Small-diameter $(<6 \mathrm{~mm})$ prosthetic arterial grafts, made exclusively from biodegradable materials, is emerging as a highly promising alternative solution that eliminates the need for harvesting patient's native tissue, and dramatically reduces risks to calcifications and infections of no biodegradable synthetic grafts. Although human clinical trials are still distant, this new approach is being actively investigated by several groups around the world. In this review, we focus on several key large animal studies from the past two decades and highlight some of the critical challenges faced in the development of small-diameter biodegradable synthetic vascular grafts.

Abbreviations: PAD: Peripheral Artery Disease; TEAG: Tissue Engineered Arterial Grafts; EC: Endothelial Cell; SMC: Smooth Muscle Cell; ECM: Extracellular Matrix; PGA: Polyglycolide; PLGA: Poly (Lactic-Co-Glycolic Acid); PCL: Polycaprolactone; PLLA: Poly-L-lactic Acid; PU: Polyurethane; CS: Chitosan; PGS: Poly (Glycerol Sebacate); EPC: Endothelial Progenitor Cell

\section{Mini Review}

Peripheral artery disease (PAD) affects 8-12 million people in the United States, especially those over 50 [1]. Currently, the most important need for adult PAD patients is the lower limb bypass surgery. Although the autologous vessels and prosthetic grafts are gold standards for bypass surgeries [2] harvesting autologous vessels in an aging population often can be challenging. For instance, older PAD patients often have poor glycemic control due to diabetes, and the use of their already damaged vessels frequently result in repeated surgeries. Non-biodegradable graft is also associated with graft infection and calcification [3]. These and other challenges associated with antilogous vessels and non- biodegradable can be, in principle, overcome with the development of biodegradable arterial prosthetic grafts. Successful development of small diameter biodegradable Tissue Engineered Arterial Grafts (TEAG) that are capable of withstanding arterial pressure will dramatically increase the patient's survival rate and quality of life. It effectively mitigates the need for multiple future operations, and by eliminating the time and effort spent in graft harvesting, it also significantly reduces the surgical duration and increases its success rate. Furthermore, the successful development and utilization of TEAG for peripheral arterial bypass surgery may eventually be adapted in the future for coronary artery bypass surgery and end stage renal disease hemodialysis as well. 
Among the existing TEAGs under consideration, biodegradable synthetic scaffolds consisting solely of polymers are the most suitable for use in clinical practice due to its economic value, ease of production, and immediate off the shelf availability as compared to cellularized or decellularized biological scaffolds. In biodegradable grafts, the degrading foreign material is gradually replaced by the host endothelial (EC), smooth muscle cells (SMC), and the extracellular matrix (ECM). While the ideal biomaterial for vascular surgery should be non-thrombogenic, non-infectious, and highly durable during and after host regeneration [4], the existing materials and approaches can often lead to several critical problems. This review focuses on large animal trials aimed at addressing two most widespread complications, the loss of mechanical property and the thrombosis of the grafts. This work covers key studies from the last twenty years that were done on canine, ovine, and porcinis.

\section{Mechanical Property Change and Tissue Regeneration}

The post implantation graft mechanical property sensitively depends on the competition between biodegradation (synthetic material) and regeneration (host tissue) rates. While it was not much of a concern during the initial human TEAG transplants in venous environments [5], the balance between these two rates become delicate in an arterial environment, where the mechanical stress on the graft is much higher. To produce a scaffold with the ability of surviving higher arterial pressure, without dilatation or burst, the electrospinning technology is commonly used on co-polymering biodegradable synthetic materials. Most research groups are currently exploring different combinations of Polyglycolide (PGA), Poly (lactic-co-glycolic acid) (PLGA), Polycaprolactone (PCL), and Poly-L-lactic Acid (PLLA) with or without natural materials such as Chitosan (CS) or Collagen (Table 1). The electrospinning method, originally developed for the textile industry [6], is now widely employed around the world to make biodegradable arterial grafts, and it offers the capability for a high degree of customization in diverse set of synthetic and biological materials. While it allows easier control for the fiber diameter, which is critical in producing scaffolds of optimal thickness and tensile strength suitable for the arterial environment, one notable challenge with the electrospinning approach has been the difficulty of increasing the pore size.

Table 1: TEAGs applied in Large animal studies.

\begin{tabular}{|c|c|c|c|c|c|c|c|c|}
\hline Author & $\begin{array}{l}\text { Animal } \\
\text { Species }\end{array}$ & $\begin{array}{c}\text { Study } \\
\text { Duration }\end{array}$ & $\mathbf{n}$ & Graft type & $\begin{array}{l}\text { Graft Inner } \\
\text { Diameter }\end{array}$ & $\begin{array}{c}\text { Graft } \\
\text { length }\end{array}$ & $\begin{array}{l}\text { Implantation } \\
\text { Position }\end{array}$ & $\begin{array}{c}\text { Scaffold } \\
\text { Technology }\end{array}$ \\
\hline $\begin{array}{c}\text { Niklason, et al. } \\
{[25]}\end{array}$ & porcine & 4weeks & 4 & PGA+EC,SMC & $<6 \mathrm{~mm}$ & $3.5 \mathrm{~cm}$ & $\begin{array}{l}\text { Right } \\
\text { saphenous } \\
\text { artery }\end{array}$ & $\begin{array}{c}\text { chemically } \\
\text { modified with } \\
\text { sodium hydroxide }\end{array}$ \\
\hline $\begin{array}{c}\text { Shum Tim, et al. } \\
{[26]}\end{array}$ & ovine & 5 months & 11 & $\mathrm{PGA} / \mathrm{PHA}+\mathrm{EC}$ & $7 \mathrm{~mm}$ & $3-4 \mathrm{~cm}$ & $\begin{array}{l}\text { Abdominal } \\
\text { aorta - }\end{array}$ & - \\
\hline Zhang, et al. [10] & Canine & 24 weeks & 16 & $\begin{array}{l}\text { Three-layers of } \\
\text { porous PLGA- } \\
\text { compact } \\
\text { PUs-porous } \\
\text { PLGA+BMCS }\end{array}$ & $6 \mathrm{~mm}$ & $4 \mathrm{~cm}$ & $\begin{array}{l}\text { Abdominal } \\
\text { aorta }\end{array}$ & $\begin{array}{c}\text { dip-coating } \\
\text { inner/spraying } \\
\text { and salt leaching } \\
\text { outer layer }\end{array}$ \\
\hline Yokota, et al [13] & canine & 12 months & 16 & $\begin{array}{l}\text { PGA/PLA }+ \\
\text { Collagen sponge }\end{array}$ & $4 \mathrm{~mm}$ & - & Carotid artery & Air jet spinning \\
\hline Huang, et al. [23] & canine & 3 months & 8 & $\begin{array}{l}\text { Heparin loaded } \\
\text { P[LLA-CL]+EC }\end{array}$ & $4 \mathrm{~mm}$ & - & $\begin{array}{l}\text { Femoral } \\
\text { artery }\end{array}$ & $\begin{array}{c}\text { coaxial } \\
\text { electrospun }\end{array}$ \\
\hline Zhou, et al.[20] & canine & 3 months & 6 & $\mathrm{PCL} / \mathrm{CS}+\mathrm{EC}$ & $3 \mathrm{~mm}$ & $4-5 \mathrm{~cm}$ & Carotid artery & eletrospun \\
\hline Zhai, et al.[26] & canine & 1 month & 8 & $\begin{array}{l}\text { Heparin loaded } \\
\text { P[LLA-CL]+EC }\end{array}$ & $2.5-3.5 \mathrm{~mm}$ & $5 \mathrm{~cm}$ & $\begin{array}{l}\text { Femoral } \\
\text { artery }\end{array}$ & $\begin{array}{c}\text { coaxial } \\
\text { electrospun }\end{array}$ \\
\hline Wang, et al.[24] & canine & 24 weeks & 20 & $\begin{array}{l}\text { Heparin loaded } \\
\text { P[LLA-CL] } \\
\text { +polyurethane, } \\
\text { collagen }\end{array}$ & $4 \mathrm{~mm}$ & $5-6 \mathrm{~cm}$ & $\begin{array}{l}\text { Femoral } \\
\text { artery }\end{array}$ & $\begin{array}{l}\text { coaxial } \\
\text { electrospun }\end{array}$ \\
\hline $\begin{array}{c}\text { Mrówczynski, et } \\
\text { al.[17] }\end{array}$ & Porcine & 1 month & 11 & PCL & $4 \mathrm{~mm}$ & $8 \mathrm{~cm}$ & Carotid artery & electrospun \\
\hline $\begin{array}{c}\text { Fukunishi, et al. } \\
\text { [27] }\end{array}$ & Ovine & 6 months & 6 & $\mathrm{PCL} / \mathrm{CS}$ & $5 \mathrm{~mm}$ & $1.5 \mathrm{~cm}$ & Carotid artery & electrospun \\
\hline Siang Ong, [28] & Ovine & 4 weeks & 6 & PGA/PLCL+BMCS & $3 \mathrm{~mm}$ & $5 \mathrm{~cm}$ & $\begin{array}{c}\text { Carotid } \\
\text {-external } \\
\text { jugular vein } \\
\text { AVF }\end{array}$ & electrospun \\
\hline Min Ju, et al. [21] & Ovine & 6 months & - & $\begin{array}{c}\text { - PCL+EC, SMC + } \\
\quad \text { Collagen }\end{array}$ & $4.75 \mathrm{~mm}$ & $5 \mathrm{~cm}$ & Carotid artery & eletrospun \\
\hline
\end{tabular}


Too small pores can halt cell infiltration - the initial step of vascularization and regeneration. Several methods have been explored to overcome this problem, such as salt leaching technique $[7,8]$, laser radiation [9] and modifications to machine settings. For instance, when highly durable materials like PLGA and Polyurethane (PU) were constructed together and used salt leaching technique [10] to modify the pore sizes. Salt leaching technique increases scaffold pore sizes by adding salt particles and dissolving in the pre or leaching out salt particles in the post-polymer network creation stage [11]. Although, the rate of inflammation was found to be too high and the rate of regeneration too low. The compliance was shown to be lesser than native carotid arteries, which could be in part due to the slow degradation of PLGA and PU. However, a possible solution to this problem was reported by Wang et al [12], who modified the electrospinning condition with a thicker mat to produce durable PCL with larger diameter fibers and pores without a need of using other highly durable materials. The testing on rat abdominal aorta resulted in enhanced cell infiltration and vascularization similar to native aorta, as compared to thin diameter fibers with small pores. Although this is a highly promising result, extensive large animal model testing with synthetic materials with large pores and thick fibers are required to further verify the validity of this approach.

Vascular regeneration consists from EC, SMC, and ECM (collagen and elastin), where elastin and SMC play a key role in vascular compliance. In most large animal studies, the regeneration is dominated by collagen and SMC, while elastin lags behind $[13,14]$. For instance, when tested the PLLA/PGA copolymer with collagen micro sponge, the SMC and the collagen contents were similar to native carotid arteries, however, the elastin content tended to plateau only in 4 months of time [14]. It was speculated that the remaining slow degrading stiff layer of synthetic material might have prevented the transmission of sheer stress and pulsatile pressure to the scaffold wall [13]. Cross-linked elastin network is highly complex process and one of the biggest difficulties often faced in large animal studies [9]. A possible culprit for this problem has been hypothesized to be the fast degradation rate by the Wang et al [15], who have tested Poly (glycerol sebacate) (PGS), the fastest degrading material, with PCL sheath to prevent immediate bleeding. Result of post 3-month rat abdominal aorta implantation had shown compliant mechanical strength with synchronous pulsation due to higher expression of elastin. Currently the effect of fast degrading material has not been tested on large animals, where the regeneration rate is much slower than in a rat. Extremely fast degrading materials like PGS may not be suitable in a large animal setting [16]. In summary, these findings suggest to explore following two aspects in future large animal studies: (1) the effect of relatively faster degrading material for compliant vascular mechanical property with a careful consideration of large animal physiological slower regeneration rate; (2) the effect of fibers with larger pores and greater diameters for sufficient cell infiltration.

\section{Possible Solutions to Thrombosis}

One of the major early stage challenges arising from the hydrophobic nature of the synthetic arterial grafts is thrombosis. This is well illustrated in a recent study [17] that performed a porcine carotid artery implantation of a small PCL scaffold 4-mm in diameter. Although an ideal late-term patency was found, PCL grafts were clearly shown to be susceptible to macrophage infiltration and thrombosis, due to graft hydrophobicity and the slow degradation rate. The results indicated that single PCL graft materials should overcome its shortcomings by exploring cellular (EC and or SMC) or chemical surface modifications, and also by copolymering different materials. The steppingstone for thrombus formation is often the deposition of platelets to the scaffold wall, and early endothelization is found to be crucial to pre-layer the scaffold interior through autologous endothelial or bone marrow cells. We note that, while anticoagulant drugs are frequently used to avoid early thrombosis, there are number of studies [18-20] that found ideal patency rate without drug prevention, but with endothelization. There are two types of endothelial progenitor cells that can be seeded into scaffolds in vitro, endothelial progenitor cells and outgrowth endothelial cells. The outgrowth endothelial cells have a superior profile in terms of vascular regeneration and cellular marker expression, showing a high degree of similarity to well-differentiated endothelial cells. PCL/CS was seeded with outgrowth endothelial cells and transplanted into the canine carotid artery [20], and 83\% was patent at 3 months, as compared to only $16 \%$ in unseeded PCL/CS of the control group.

Subsequently, Young Min Ju group has developed different pore size double-layered scaffolds seeded with autologous endothelial progenitor cell (EPCs) derived endothelial cells (ECs) and smooth muscle cells (SMCs), and then pretreated in a pulsatile bioreactor [21]. The lumen of the carotid artery at 6 months post-transplantation was covered by a mature EC, a proliferated middle layer of smooth muscle, and a collagenous outer layer, not only shown to be similar to the native vascular structure, but also the lumen of the graft was shown to be stable with no dilatation or narrowing throughout the study. These encouraging results warrant further explorations into outgrowth endothelial cells, double seeded scaffolds with SMC and their pretreatment in pulsatile bioreactor. Since the surface of most polymers in bio synthetic scaffold is hydrophobic, a weak interaction with fluid makes platelets deposit on the surface relatively quickly [22]. An emerging new approach to reduce the risk of thrombosis is the conjugation of heparin, a powerful anticoagulant, into the vascular lumen through coaxial electrospinning method. The release rate of the drug and its effect on the patency rate is currently being actively investigated. In a study that compared PLLA/CL scaffolds with loading heparin to its pre-endothelialized versions, has found that most of the release $(68 \%)$ takes place by the first week with a graft patency rate of $100 \%$. However, only $6 \%$ more was released in the second week, and the patency rate dropped to $50 \%$. 
A high release rate seems to not have a significant effect on the patency rate in the longer term, and in fact, better tensile properties were observed in the pre-endothelialized grafts in 3 months, as compared to heparin bonded ones [23]. However, a recent new study compared seeded heparin bonded PLLA/CL grafts with nonseeded group [24]. The inner layer of the graft was constructed with heparin bonded PLLC/CL nanofibers through coaxial electrospinning, and was embedded in an outer layer of woven PLLA/CL. For the first time, the heparin release was observed to be released sustainably throughout 12 weeks in pre-endotheliliazed heparin group, significantly longer than the early thrombotic period of about a month. Furthermore, the seeded heparin bonded graft patency was superior to non-seeded heparin group, with $88.9 \%$ patency rate in 24 weeks of observation as compared to $66.7 \%$. These advances suggest that pre-endotheliliazation could be the key to sustaining the heparin release during the first month and to improving the long-term patency rate.

In conclusion, united application of heparin loading and double layered pre-endothelialization with outgrowth endothelial cells and SMC to be a highly promising path for the possible thrombosis prevention.

\section{Conclusion}

This review focuses on the two most common challenges faced in large animal studies of biodegradable synthetic TEAGs: loss of mechanical properties and graft thrombosis. In order to solve these problems, different groups have tried to change the strength, the elasticity and the surface properties of the scaffold and beginning to report promising results. Validating these preliminary findings in large-scale animal models will be a major step in pushing the development of bio synthetic TEAG a step closer to clinical use.

\section{Acknowledgements}

"This research is supported by GUNZE co ltd. Specifically GUNZE co ltd provided material support through the creation of the biodegradable patch. AU and YM were supported by Department of Defense (DoD) and YU was supported by Funding award from Uehara Memorial Foundation (Tokyo Japan) in 2019.

\section{Conflict of Interest}

“The authors have read the journal's policy and the authors of the manuscript have the following competing interests: TS have received grant support from Gunze Ltd. No authors have received salary support from Gunze Ltd. This does not alter our adherence to policies on sharing data and materials. There are no patents, products in development, or marketed products to declare."

\section{References}

1. Levine GN, Bates ER, Bittl JA, Ralph G Brindis, Stephan D Fih, et al. (2016) ACC/AHA Guideline Focused Update on Duration of Dual Antiplatelet Therapy in Patients With Coronary Artery Disease: A Report of the American College of Cardiology/American Heart Association Task Force on Clinical Practice Guidelines: An Update of the 2011 ACCF/ AHA/SCAI Guideline for Percutaneous Coronary Intervention, 2011
ACCF/AHA Guideline for Coronary Artery Bypass Graft Surgery, 2012 ACC/AHA/ACP/AATS/PCNA/SCAI/STS Guideline for the Diagnosis and Management of Patients With Stable Ischemic Heart Disease, 2013 ACCF/AHA Guideline for the Management of ST-Elevation Myocardial Infarction, 2014 AHA/ACC Guideline for the Management of Patients With Non-ST-Elevation Acute Coronary Syndromes, and 2014 ACC/AHA Guideline on Perioperative Cardiovascular Evaluation and Management of Patients Undergoing Noncardiac Surgery. Circulation 134(10): e123-e155.

2. Hirsch AT, Haskal ZJ, Hertzer NR, Curtis W Bakal, Mark A Creag, et al. (2005) ACC/AHA Practice Guidelines for the management of patients with peripheral arterial disease (lower extremity, renal, mesenteric, and abdominal aortic): a collaborative report from the American Association for Vascular Surgery/Society for Vascular Surgery, Society for Cardiovascular Angiography and Interventions, Society for Vascular Medicine and Biology, Society of Interventional Radiology, and the ACC/ AHA Task Force on Practice Guidelines (Writing Committee to Develop Guidelines for the Management of Patients With Peripheral Arterial Disease): endorsed by the American Association of Cardiovascular and Pulmonary Rehabilitation; National Heart, Lung, and Blood Institute; Society for Vascular Nursing; Trans Atlantic Inter-Society Consensus; and Vascular Disease Foundation. Circulation 113(11): e463-e654.

3. Piffaretti G, Dorigo W, Ottavi P (2019) Prevalence and risk factors for heparin -bonded expanded polytetrafluoroethylene vascular graft infection after infrainguinal femoropopliteal bypasses. J Vasc Surg 70(4): 1299-1307.

4. Matsuzaki Y, Kelly J, Shoji T, Shinoka T (2019) The Evolution of Tissue Engineered Vascular Graft Technologies: From Preclinical Trials to Advancing Patient Care. Appl Sci 9(7): 1274.

5. Hibino N, McGillicuddy E, Matsumura G (2010) Late-term results of tissue -engineered vascular grafts in humans. The Journal of thoracic and cardiovascular surgery 139(2): 431-436.

6. Hasan A, Memic A, Annabi N, Monowar Hossain, Arghya Paul, et al. (2014) Electrospun Scaffolds for Tissue Engineering of Vascular Grafts. Acta biomaterialia 10(1): 11-25.

7. Baker BM, Gee AO, Metter RB, Nathan AS, Marklein RA, et al. (2008) The potential to improve cell infiltration in composite fiber-aligned electrospun scaffolds by the selective removal of sacrificial fibers. Biomaterials 29: 2348-2358.

8. Wang K, Xu M, Zhu MF, Hong Su, Wang HJ, et al. (2013) Creation of macropores in electrospun silk fibroin scaffolds using sacrificial PEO microparticles to enhance cellular infiltration. J Biomed Mater Res A 101: 3474-3481.

9. Lee BLP, Jeon H, Wang A, Yan Z, Yu J, et al. (2012) Femto second laser ablation enhances cell infiltration into three-dimensional electrospun scaffolds. Acta Biomaterial 8: 2648-2658.

10. Liang Z, Jianye Z, Qingping L, Yingjie, Shengshou Hu, et al. (2007) A Novel Small-Diameter Vascular Graft: In Vivo Behavior of Biodegradable Three-Layered Tubular Scaffolds. Biotechnol Bioeng 99(4): 1007-1015.

11. Annabi N, Nichol JW, Zhong X, Ji C, Koshy S, et al. (2010) Controlling the porosity and micro architecture of hydro gels for tissue engineering. Tissue Engineering - Part B: Reviews 16(4): 371-383.

12. Zhihong W, Yun C, Jianing W, Xiaohu, Kai Wang, et al. (2014) The effect of thick fibers and large pores of electrospun poly( $\varepsilon$-caprolactone) vascular grafts on macrophage polarization and arterial regeneration, Biomaterials 35: 5700-5710.

13. Yokota T, Ichikawa H, Matsumiya G, Toru Kuratani, Taichi Sakaguchi, et al. (2008) In situ tissue regeneration using a novel tissue-engineered, small caliber vascular graft without cell seeding. J Thorac Cardiovasc Surg 136(4): 900-907.

14. Torikai, K, Ichikawa H, Hirakawa, K, Goro Matsumiya, Toru Kuratani, et al. (2008) A self renewing, tissue-engineered vascular graft for arterial reconstruction. J Thorac Cardiovasc Surg 136(1): 37-45.

15. Chelsea S, Yadong W (2018) Quickening: Translational Design of Resorbable Synthetic Vascular Grafts. Biomaterials 173: 71-86. 
16. Wei W, Robert A, Yadong W (2012) Fast degrading elastomer enables rapid remodeling of a cell-free synthetic graft into a neo-artery. Naturemedicine 18(7): 1148-1153.

17. Mrowczynski W, Mugnai D, de Valence S, Jean-Christophe Tille, Ebrahim Khabiri, et al. (2014) Porcine carotid artery replacement with biodegradable electrospun poly-e-caprolactone vascular prosthesis. J Vasc Surg. 59(1): 210-219.

18. Takenori Y, Hajime I, Goro M, Toru Kuratani, Taichi Sakaguchi, et al. (2008) In situ tissue regeneration using a novel tissue-engineered, small-caliber vascular graft without cell seeding. J Thorac Cardiovasc Surg 136(4): 900-907.

19. Matsumura G, Isayama N, Matsuda S, Kensuke Taki, Yuki Sakamoto, et al. (2013) Long-term results of cell-free biodegradable scaffolds for in situ tissue engineering of pulmonary artery in a canine model. Biomaterials 34: 6422-6428.

20. Zhou, M, Qiao W, Liu Z, Tao Shang, Tong Qiao, et al. (2014) Development and in vivo evaluation of small-diameter vascular grafts engineered by outgrowth endothelial cells and electrospun chitosan/poly(epsiloncaprolactone) nano fibrous scaffolds. Tissue Eng Part A. 20(1-2): 79-91.

21. Young J, Hyunhee A, Juan A, Cheil K, Mehran Abolbashari, et al. (2017) Electrospun vascular scaffold for cellularized small diameter blood vessels: A preclinical large animal study. Acta Materialia. 59: 58-67.

22. Lindholt JS, Gottschalksen B, Johannesen N, D Dueholm, H Ravn, E D Christensen, et al. (2011) The Scandinavian PROPATEN ${ }^{\circledR}$ Trial - 1-year patency of PTFE vascular prostheses with heparin-bonded luminal

ISSN: $2574-1241$

DOI: 10.26717/BJSTR.2020.28.004617

Toshiharu Shinoka. Biomed J Sci \& Tech Res

CC This work is licensed under Creative

Submission Link: https://biomedres.us/submit-manuscript.php surfaces compared to ordinary pure PTFE vascular prostheses - A randomized clinical controlled multi-centre trial. European Journal of Vascular \& Endovascular Surgery 41(5): 668-673.

23. Chen H, Sheng W, Lijun Q Qinfei Ke, Wei Zhai, et al. (2013) Heparin loading and Pre-endothelialization in Enhancing the Patency Rate of Electrospun Small-Diameter Vascular Grafts in a Canine Model. ACS Appl Mater Interfaces 5: 2220-2226.

24.Wang S, Mo XM, Jiang B, Cheng J Gao, Hong S Wang, et al. (2013) Fabrication of small diameter vascular scaffolds by heparin-bonded P(LLA-CL) composite nanofibers to improve graft patency. Int ] Nanomed. 8: 2131-2139.

25. Niklason LE, Gao J, Abbott WM, KK Hirschi, S Houser, et al. (1999) Functional arteries grown in vitro. Science 284(5413): 489-493.

26. Shum Tim D, StockU, Hrkach J, J Lien, M A Moses, et al. (1999) Tissue engineering of autologous aorta using a new biodegradable polymer Ann Thorac Surg 68(6): 2298-2304.

27. Fukunishi T, Best CA, Sugiura, T, Toshihiro Shoji, Tai Yi et al. (2016) Tissue engineered small diameter arterial vascular grafts from cell free nanofiber PCL/chitosan scaffolds in a sheep model. PLoS One 11(7): e0158555.

28. Siang Ong C, Fukunishi T, Han Liu R, Kevin Nelson, Huaitao Zhang, et al. (2017) Bilateral Arteriovenous Shunts as a Method for Evaluating Tissue-Engineered Vascular Grafts in Large Animal Models. TISSUE ENGINEERING 23(11): 728-735.

$\begin{array}{ll}\text { BIOMEDICAL } & \text { Assets of Publishing with us } \\ \text { RESEARCHES } & \text { - Global archiving of articles } \\ & \text { - Immediate, unrestricted online access } \\ & \text { - Rigorous Peer Review Process } \\ & \end{array}$

